\title{
Experiência com extensão rural agroecológica em assentamento de reforma agrária
}

Experience with rural extension agroecology in land reform settlement

Autores

Ms. André Wagner Barata-Silva, mestre em Desenvolvimento Sustentável e Extensão pela UFLA; doutorando em Fitotecnia no Departamento de Agricultura da Universidade Federal de Lavras.

Email: awbaratasilva@yahoo.com.br

Dra. Viviane Santos Pereira, professora do Departamento de Administração e Economia e do programa de mestrado profissional em Desenvolvimento Sustentável e Extensão da Universidade Federal de Lavras.

Email: vivianesantospereira@yahoo.com.br

Dra. Maria de Lourdes Souza Oliveira, professora do programa de mestrado profissional em Desenvolvimento Sustentável e Extensão da Universidade Federal de Lavras.

Email: marocabj@gmail.com

Dr. Luís Cláudio Paterno Silveira, professor do Departamento de Entomologia e do programa de mestrado profissional em Desenvolvimento Sustentável e Extensão da Universidade Federal de Lavras.

Email: Icpsilveira@den.ufla.br

\section{Relato}

Esta experiência foi realizada em uma unidade produtiva no assentamento Santos Dias vinculado ao Movimento dos Sem Terra (MST), localizado no município de Guapé- MG. Teve como objetivo relatar a experiência de controle biológico conservativo de pragas agrícolas a partir da perspectiva de extensão rural agroecológica em um assentamento do movimento dos trabalhadores sem

\section{Abstract}

This experiment was performed in a production unit in the Santos Dias settlement, which is linked to the Landless Workers' Movement (MST) and located in the municipality of Guapé- MG. Its goal was to report the experiment in the conservative biological control of agricultural pests from the perspective of the agroecological extension program in one of the settlements of the Landless 
terra. Foram realizadas visitas a propriedade desenvolvendo atividades de orientação técnica, diálogo, observação e construção do saber. Esta experiência possibilitou a construção de conhecimentos por meio da interação entre universidade e sociedade.

Palavras-chave: Extensão rural, Agroecologia, Controle Biológico Conservativo.
Workers' Movement. Visits were made to the property, which led to the development of technical guidance activities, dialogue, observation and construction of knowledge. This experiment enabled the construction of knowledge through interaction between university and society.

Keywords: Rural Extension; Agroecology; Conservative Biological Control

\section{Área temática: Meio ambiente}

Linha de extensão: Desenvolvimento

rural e questão agrária.

\section{Introdução}

A área de conhecimento ciências agrárias orienta hoje a atuação de diversos agentes em seu processo de produção e transformação da natureza e, consequentemente, a vida social no campo. ${ }^{1}$ Ao longo da história, várias formas de fazer ciência tiveram implicações práticas e metodológicas no trabalho de orientação técnica e na elaboração de projetos de desenvolvimento.

Segundo Coelho', recentemente, outra forma de fazer ciência denominada ciência (com)partilhada tem a pretensão de realizar uma síntese que aumente a inserção social das práticas científicas anteriores (dominantes). Neste novo contexto, o saber é gerado por experimentações nas quais os agricultores se tornam experimentadores, parceiros e agentes das pesquisas com os pesquisadores. Essa é tendência mais recente de construção de saberes para agricultura, que aproxima o pensamento agronômico cientificado do conhecimento cotidiano, tendo como ponto de partida e de chegada a percepção e os valores culturais dos agricultores.

Ao utilizarmos o termo orientação técnica, ao invés de assistência técnica, pretende-se enfatizar que o trabalho das profissões agrárias é capaz de promover intervenções que visam, não apenas mudança na produção pela inovação técnica, mas também em questões sociais e políticas. Isto ocorre por modificarem não só habilidades manuais, mas também mentalidades, valores, formas de compreensão, de organização social e de capacidades argumentativas, tanto no técnico como no grupo social envolvido. Neste sentido, o aspecto principal da função técnica nas profissões agrárias é o que as credencia como agentes importantes em contextos de mudança social no campo. ${ }^{1}$

Diante deste contexto, exige-se uma mudança de paradigma que coloque para os 
profissionais das ciências agrárias a necessidade de uma reflexão ético-moral sobre os motivos e as consequências sociais e ambientais das orientações técnicas que prestam. Segundo Freire"2, "a capacitação técnica, que não é um processo de adestramento animal, jamais pode estar dissociada das condições existenciais dos camponeses de sua visão cultural e de suas crenças". Segundo Coelho', seguindo a senda das contradições da modernidade, mesmo no Brasil do latifúndio, experiências de natureza mais socializantes ou solidárias têm sido possíveis em alguns assentamentos de reforma agrária em determinadas regiões, como, por exemplo, no sul de Minas Gerais. Sendo assim, cabe aos profissionais das ciências agrárias terem sensibilidade e discernimento para perceber e respeitar outras opções de desenvolvimento local diferentes dos empreendimentos capitalistas no campo, ou seja, respeitar e incentivar formas solidárias de produção e comercialização. ${ }^{1}$

Para Altieri ${ }^{3}$, a agricultura camponesa está passando por um processo de empobrecimento sistemático. Frente a esta crise, uma importante medida que deveria ser tomada nos programas de desenvolvimento rural é a preservação da agricultura camponesa, tornando-a mais sustentável e produtiva.

Nesse sentido, já é possível perceber que o modelo dos pacotes tecnológicos da revolução verde, já vem sendo substituído pelos agricultores familiares por formas mais sustentáveis e ecológicas de produção agropecuária, o que tem garantido melhores condições de saúde e vida para os agricultores. ${ }^{4}$ Como exemplo, pode-se citar as práticas agrícolas de base ecológica, que se mostram mais efetivas na medida em que não causam dependência de mercados sobre os quais muitos agricultores não têm controle e utilizam métodos de produção mais integrados com a natureza. Entre estes métodos, o controle biológico conservativo de insetos herbívoros, se apresenta de forma eficiente, sustentável e de baixo custo ao produtor. Esta prática tem como objetivo atrair e fornecer as condições de sobrevivência necessárias para que os insetos reguladores naturais (parasitoides e predadores) possam permanecer na unidade produtiva e, desta forma, controlar naturalmente as populações de insetos herbívoros para que não atinjam o nível de dano econômico.

A partir do exposto, pretende-se com este trabalho, relatar uma experiência de extensão rural agroecológica baseada numa proposta científica compartilhada com os agricultores, em um assentamento do Movimento dos Trabalhadores Rurais Sem Terra (MST) desenvolvida a partir de um experimento de controle biológico conservativo de insetos herbívoros na produção de tomate orgânico.

\section{Contextualização}

Esta experiência foi realizada em uma unidade produtiva no assentamento Santo Dias vinculado ao MST, localizado no município de Guapé - MG. Este assentamento encontra-se localizado em uma região de transição entre o sudoeste e o sul de Minas Gerais, região do médio Rio Grande, às margens do reservatório de Furnas. Localiza-se no ecótono entre os domínios da Mata Atlântica e do Cerrado. O clima da região é do tipo temperado chuvoso, com precipitação média anual de $1400 \mathrm{~mm}$. O local apresenta 
uma paisagem típica de cerrado, com formações isoladas de matas que acompanham os cursos de água e de formações campestres. ${ }^{5}$

O assentamento Santo Dias possui uma área total de 1.788 hectares. Surgiu no ano de 2002, a partir de um acampamento em uma área que antigamente fazia parte de uma usina de cana- de- açúcar. O local foi ocupado inicialmente com 49 famílias de trabalhadores e trabalhadoras rurais, organizados em núcleos de famílias e setores de organização interna. No início, a comunidade estava organizada numa estrutura de agrovila, onde as casas de alvenaria e barracos de lona ficavam dispostos próximos uns dos outros. Dessa forma, a produção agrícola era realizada em lotes provisórios individuais e num lote coletivo de 12,5 hectares, onde se cultivava arroz, feijão e milho. Algumas famílias possuíam gado para produção de leite para consumo interno e o rebanho era criado em pastagem coletiva, apesar de os animais serem de propriedade individual. Ainda entre as atividades desenvolvidas coletivamente estavam uma horta de espécies olerícolas e plantas medicinais. ${ }^{6}$

A partir do ano de 2007, quando os produtores passaram para a condição de assentados, o trabalho passou a ser feito nos lotes individuais das famílias; no entanto, se manteve o cultivo coletivo de determinadas culturas em áreas de produção coletiva, com destaque para a produção orgânica agroecológica de cana- de- açúcar, assim como a produção de sementes de hortaliças orgânicas.

É importante dizer que o assentamento, desde sua implantação, adotou a agroecologia como base científica para orientar as formas de manejo realizadas no assentamento. Devido a isso, foi estabelecido entre os assentados o não uso de agroquímicos e queimadas dentro do assentamento. Atualmente este assentamento possui várias áreas certificadas de forma participativa pelo OPAC Sul de Minas para produção orgânica. No ano de 2014, a direção nacional do MST destacou o assentamento Santo Dias como exemplo de manejo produtivo agroecológico.

O relato desta experiência inicia-se a partir do contato com os agricultores que estavam envolvidos na produção de sementes biodinâmicas de tomate. Neste momento, foi construído e realizado com os agricultores um experimento de controle biológico conservativo de insetos herbívoros na sua área de produção. O objetivo desta experiência era compreender a influência do plantio em consórcio entre tomate e coentro na dinâmica populacional de insetos. Ao longo da realização do experimento por meio de metodologias participativas foi possível criar espaços de diálogo e reflexão entre os pesquisadores (Universidade) e os agricultores (Sociedade) numa interação entre o conhecimento científico e o saber tradicional. Neste relato serão abordados os caminhos de construção desta experiência compartilhada.

\section{Extensão rural agroecológica em assentamento de reforma agrária}

Os caminhos percorridos para realização das atividades de pesquisa em interface com extensão, contaram com métodos específicos, ora de pesquisa experimental, ora de pesquisa em ciências sociais ora utilizados de forma simultânea, como será apresentado a seguir. A preocupação central foi refletir com as famílias envolvidas na produção 
de sementes sobre as informações que eram geradas durante o desenvolvimento do trabalho, tanto sobre a experimentação de controle biológico quanto sobre suas realidades sociais e histórias de vida.

A complexidade do espaço socioambiental encontrado foi apontando especificidades importantes na construção da melhor forma de condução do experimento de controle biológico conservativo. Um dos pressupostos que orientou o trabalho foi o de que não é possível simplesmente transpor um "modelo experimental" entre realidades sociais distintas. Um assentamento de reforma agrária comporta dimensões de solidariedade, conflito, resistência, criticidade e lutas não necessariamente presentes em outros espaços rurais, ou até em outros assentamentos. Observar as perspectivas dos atores sociais envolvidos foi o foco a ser buscado sistematicamente durante todas as fases do trabalho.

Entendemos que a extensão exercitada pelas Universidades na sua relação com a sociedade tem papel de transformação no sentido de mudança social" , e também na construção conjunta de conhecimentos. Este trabalho de pesquisa em interface com a extensão foi desenvolvido por meio das seguintes atividades: implantação de um experimento entomológico; observação participante durante as vivências no assentamento; oficinas participativas com atividades teóricas e práticas sobre a temática do controle biológico conservativo; realização de entrevistas semi-estruturadas. A Tabela 1 apresenta um resumo das atividades realizadas.

\section{Data}

Atividades

\begin{tabular}{|c|c|}
\hline & Primeiro contato com os agricultores, proposta da pesquisa \\
\hline 20/06/2014 & $\begin{array}{l}1^{\text {a }} \text { Vivência no assentamento, avaliação do campo de produção, oficina } \\
\text { teórica de controle biológico conservativo. }\end{array}$ \\
\hline $28 / 08 / 2014$ & Definição da área do experimento com os agricultores \\
\hline $01 / 10 / 2014$ & Reformulação do experimento com os agricultores \\
\hline $03 / 10 / 2014$ & Coleta dos insetos, troca de experiência com os agricultores \\
\hline $10 / 10 / 2014$ & Coleta dos insetos, troca de experiência com os agricultores \\
\hline $17 / 10 / 2014$ & Coleta dos insetos, troca de experiência com os agricultores \\
\hline 24/10/2014 & Coleta dos insetos, troca de experiência com os agricultores \\
\hline 24/10/2014 & Participação na visita de pares do processo de certificação orgânica \\
\hline $31 / 10 / 2014$ & Coleta dos insetos, troca de experiência com os agricultores \\
\hline $08 / 11 / 2014$ & Coleta dos insetos, atividade prática no campo \\
\hline $17 / 12 / 2014$ & Participação na visita de verificação do OPAC- Sul de Minas \\
\hline $16 / 05 / 2015$ & Participação reunião grupo de mulheres, escolha dos entrevistados \\
\hline $25 / 06 / 2015$ & Realização das entrevistas com os agricultores (as) \\
\hline $26 / 06 / 2015$ & Realização das entrevistas com os agricultores (as) \\
\hline $26 / 06 / 2015$ & Participação na festa Junina do assentamento \\
\hline $23 / 10 / 2015$ & Participação na visita de verificação do OPAC- \\
\hline
\end{tabular}

Tabela 1: Atividades realizadas na construção da pesquisa compartilhada

O experimento entomológico foi realizado em campo com a participação dos trabalhadores rurais que compartilharam os desafios na condução, assim como os limi- 
tes e os avanços possíveis. Os diálogos com os agricultores inspiraram caminhos antes não previstos e metodologicamente foram acolhidos e interagiram com as observações científicas de forma dialética e constante. O detalhamento será exposto a seguir.

O primeiro contato com a família, proprietária do lote no qual foi instalado o experimento, ocorreu no dia 07/03/2014. Foi sugerido aos agricultores a realização de um projeto de pesquisa compartilhada de controle biológico conservativo de insetos herbívoros com interface a extensão rural, na área de produção de sementes de hortaliças orgânicas. Os agricultores demonstraram grande interesse na realização desta pesquisa; sendo assim, foi marcada uma visita para conhecer o local e planejar o experimento.

O primeiro contato com a comunidade e com a área de produção ocorreu no dia 20/06/2014. Neste dia, foi realizada a avaliação do campo de produção de sementes de hortaliças e foram entregues aos agricultores duzentas mudas da planta cravo amarelo (Tagetes erecta) que seriam posteriormente plantadas no local do experimento com a função ecológica de atrair os insetos reguladores naturais. Neste mesmo dia, por demanda da comunidade, foi construída uma oficina participativa sobre o tema controle biológico conservativo de insetos herbívoros. Nesta oficina foram apresentados os conceitos básicos desta forma de manejo de insetos, assim como, discutiu-se sobre a importância da diversificação vegetal nas áreas de produção. A tônica da oficina foi o diálogo numa perspectiva de intervenção participativa, ou seja, não agir da forma que o autor Freire², chama de "educação bancária" ou "domesticação", que é caracterizada pela prática da transmissão do conhecimento "de cima para baixo" em que quem "sabe" (técnicos) ensina a quem "não sabe" (agricultor) num processo vertical como agiam e ainda age grande número de extensionistas. Nesse sentido, Gomes ${ }^{8}$ argumenta que a consideração do social e do humano na ciência e na produção do conhecimento não pode ficar muito subjetiva e não visível, pois é preciso tentar mudar a situação de maneira a produzir a ciência no mundo da vida.

O segundo encontro ocorreu no dia 28/08/2014, em que foi definido em conjunto com os produtores a área plantada com tomate para implantação do experimento. Neste dia foi realizado o plantio das mudas de cravo amarelo, em uma das parcelas entre as plantas de tomate.

Na visita do dia 01/10/2014, foi observado que as plantas de cravo amarelo não apresentaram o desenvolvimento esperado; sendo assim, houve a necessidade de rediscutir com os agricultores outra possibilidade para a realização do experimento. Após conversa com os produtores foi definido realizar o experimento na área de produção de tomate em consórcio com coentro, ambos visando o aproveitamento das sementes para comercialização. Neste caso, o coentro também é uma planta que exerce a função ecológica de atração de insetos reguladores. A proposta inicial de utilizar o cravo amarelo como fator de diversificação vegetal foi substituída pelo uso do próprio coentro. Sendo assim, a área de produção de tomate foi dividida pela metade em duas parcelas e todas as plantas de coentro foram retiradas de uma das parcelas formando dois tratamentos (monocultura e consórcio). Posteriormente foram instaladas 16 armadilhas do tipo Moericke para coleta dos insetos, sendo oito armadilhas para cada tratamento, explicando-se aos agricultores a função das armadilhas e como montá-las. Foi combinado que os agricultores 
assumiriam a responsabilidade no processo de coleta de dados, participando das atividades de campo do projeto. Eles ficaram responsáveis por colocarem as armadilhas no campo quarenta e oito horas antes do dia marcado para a coleta dos insetos, que foram realizadas pelos pesquisadores. A partir da instalação das armadilhas, foram iniciadas as coletas semanais dos insetos. As coletas entomológicas foram realizadas em seis momentos (quadro 1), sempre com a participação dos agricultores. Após o trabalho de campo, era rotina o diálogo e troca de experiências com a comunidade.

É importante destacar que o ciclo de produção do tomate, consequentemente o número de coletas, foi abreviado devido a uma infecção da lavoura por um vírus do gênero Tospovirus sp. que é transmitido pelo inseto denominado tripes e manifesta na planta a doença conhecida como vira cabeça do tomateiro. ${ }^{9}$ A incidência desta doença na área de produção de tomate impediu a comercialização das sementes; no entanto, a polpa do fruto foi utilizada para a produção e comercialização de 180 quilos de molho de tomate orgânico.

No dia 08/11/14, foi realizada uma atividade prática sobre controle biológico conservativo no local do experimento. Nesta atividade, foi explicado e demonstrado, em que consiste esta forma de controle e a importância de diversificar as áreas de produção. Foram apresentados os insetos reguladores naturais de insetos herbívoros, também conhecido por eles como insetos "amigos do produtor". Nesta prática de campo, foram levados insetos criados no Departamento de Entomologia da Universidade Federal de Lavras (UFLA), para que eles pudessem ver com o auxílio de uma lupa os insetos predadores conhecidos popularmente como joaninha (Coleoptera, Coccinellidae) e bicho lixeiro (Neuroptera, Chrysopidae) e os parasitoides (Hymenoptera) predarem e parasitarem os pulgões (insetos herbívoros) (Hemiptera, Aphidoidea).

Após o trabalho com a lupa, foi realizada a observação dos insetos entomófagos no agroecossistema. No final da atividade foram distribuídas para cada produtor três cartilhas confeccionadas pela engenheira agrônoma Rebeca Andrade. Estas cartilhas tiveram o objetivo de ajudar o agricultor a reconhecer no ambiente natural os insetos benéficos; além disso, apresenta métodos de manejo da lavoura para atrair os insetos reguladores naturais.

Outra experiência importante foi a participação na primeira visita de pares e de verificação realizada pelo OPAC Sul de Minas, com o objetivo de realizar a avaliação da conformidade orgânica para a certificação de áreas no assentamento. Foi uma oportunidade de conhecer mais a fundo os agricultores envolvidos neste processo, assim como suas propriedades. É importante ressaltar que a forma de certificação participativa preconiza o envolvimento dos agricultores em todo o processo de certificação, criando deste modo oportunidades de troca de experiências e saberes com agricultores orgânicos de outras regiões do Sul de Minas. Todo este intercâmbio é extremamente valorizado entre eles, que dizem aprender muito com a experiência de outros agricultores, além de se sentirem motivados a melhorar seus sistemas de produção.

Como última atividade do ano de 2014, os pesquisadores participaram de uma reunião do grupo Olhos D'água: produzindo e preservando, formado pelas mulheres do assentamento, este grupo se caracteriza por ser muito ativo no assentamento e estar bastante envolvido com a produção orgânica. Foi um momento de perceber a visão das agricul- 
toras com relação a temas relevantes como: segurança alimentar, gênero, participação, produção de sementes e agroecologia. Neste mesmo dia, foi realizado um encontro com os agricultores e agricultoras que estavam envolvidos com a pesquisa, com o objetivo de tentar compreender a realidade da produção orgânica no assentamento e de identificar agricultoras e agricultores dispostos a participar de uma entrevista mais aprofundada.

No ano de 2015, nos dias 25 e 26 de Junho, foram realizadas no assentamento as entrevistas com as agricultoras e agricultores. O processo de entrevistar foi um momento muito rico de diálogo. Foi um momento que possibilitou aprofundar o olhar sobre a realidade social que envolve o tema pesquisado, abrindo com isso, novos e surpreendentes caminhos que foram trilhados. Nesta perspectiva, foi observado conforme falam Günther ${ }^{10}$ e Chaer ${ }^{11}$ que o uso complementar de métodos qualitativos e quantitativos possibilita um resultado mais considerável e significativo da questão de pesquisa.

\section{Considerações Finais}

A realização desta experiência compartilhada foi uma oportunidade muito positiva para todos os envolvidos no processo de construção do conhecimento, pois possibilitou um contato maior com a realidade dos produtores familiares assentados da reforma agrária que optaram por produzir alimentos através de um manejo agroecológico de produção. Para os produtores ressalta-se a oportunidade de interação com a universidade, via troca de experiências, acesso a informações técnicas para solução de problemas e a percepção da importância da diversificação vegetal em suas áreas de produção como estratégia para atrair e manter os insetos reguladores naturais, com o objetivo de diminuir a incidência de insetos herbívoros.

A oportunidade de realização de uma pesquisa compartilhada - na qual a troca de saberes e experiências entre técnicos e agricultores ocorre de forma horizontal, dentro da realidade dos agricultores, que são os que verdadeiramente devem se beneficiar dos resultados da pesquisa - possibilitou ao pesquisador- extensionista aguçar a visão crítica com relação à forma de fazer pesquisa e para quem se faz ciência pelas universidades e centros de pesquisa públicos. Além disso, possibilitou ter uma percepção mais clara das dificuldades que os produtores orgânicos assentados da reforma agrária encontram. No entanto, o mais importante foi vivenciar as qualidades que os (as) camponeses (as) possuem na leitura e no manejo do agroecossistema, assim como sua dedicação e entusiasmo na construção de uma agricultura sustentável.

\section{Referências}

1. COELHO, France Maria. A arte das orientações técnicas no campo: concepções e métodos. 2.ed. Viçosa: Suprema, 2014. 188 p.

2. FREIRE, Paulo. Extensão ou Comunicação? 7.ed. Rio de Janeiro: Paz e Terra, 1983. 93 p.

3. ALTIERI, M. A. Agroecologia, a dinâmica produtiva da agricultura sustentável. Porto Alegre: Editora da Universidade - UFRGS, 2001. 54 p. 
4. SILIPRANDI, E. Mulheres e Agroecologia: Transformando o Campo, as Florestas e as Pessoas. Rio de Janeiro: UFRJ. 2015. 352p.

5. TORRES, D. M.; SANSONAS, H. P.; FONTES, M. A. L. A Troca de Experiências Entre Estudantes e Camponeses Através do Estudo da Vegetação do Assentamento Santo Dias, Guapé, MG. In: VI Congresso Brasileiro de Agroecologia, 9., 2009, Rio de Janeiro. Anais..., Rev. Bras. De Agroecologia, 2009. Vol. 4 No. 2. p. 629-631.

6. MAGRINI, P. R.; OLIVEIRA, M. L. S.; PROENÇA, I. C. L.; PEDRO, I. K. A. Tecendo enfrentamentos e solidariedade em um assentamento do MST no Sul de Minas Gerais. In: Congresso Brasileiro de Sociologia, 2009, Rio de Janeiro. Anais..., Rio de Janeiro: CBS, 2009. p. 01-01.

7. FÓRUM DE PRÓ-REITORES DE EXTENSÃO DAS UNIVERSIDADES PÚBLICAS BRASILEIRAS. Política Nacional de Extensão Universitária. Manaus: FORPROEX; 2012. Disponível em: http://www.renex.org.br/documentos/2012-07-13-Politica-Nacional-de-Extensao.pdf. Acesso em: 16 de setembro de 2016.

8. GOMES, J. C. C. Bases epistemológicas da agroecologia. In: Aquino, A. M.; Assis, R. L. (Org.). Agroecologia: princípios e técnicas para uma agricultura orgânica sustentável. Brasília: Embrapa Informação Tecnológica, 2005. 517 p.

9. MOURA, A. P. et al. Manejo integrado de pragas do tomateiro para processamento industrial. Brasília: Embrapa, 2014. 24 p.

10. GÜNTHER, H. Pesquisa Qualitativa versus Pesquisa Quantitativa: Esta é a questão? Psic.: Teoria e Pesquisa, Brasília, Vol. 22, n. 2, p. 201-210, 2006.

11. CHAER, G. ET AL. A técnica do questionário na pesquisa educacional. Evidência, Araxá, v. 7, n. 7, p. 251-266, 2011. 